\title{
XVI. A theory of glacier motion
}

\section{R. Mountford Deeley F.G.S.}

To cite this article: R. Mountford Deeley F.G.S. (1888) XVI. A theory of glacier motion , Philosophical Magazine Series 5, 25:153, 156-162, DOI: 10.1080/14786448808628162

To link to this article: http://dx.doi.org/10.1080/14786448808628162

$$
\text { 册 Published online: } 29 \text { Apr } 2009 .
$$

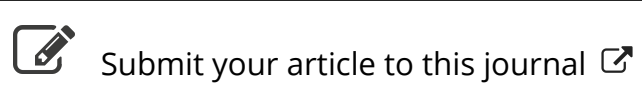

\footnotetext{
Џll Article views: 3
}

Q View related articles $\sqsubset$ 
explanation of why Sir W. Thomson did not introduce selfinduction into his theory. There were presumably more ways than one of doing it, as regards the measure of the electric force of induction. When we follow Maxwell's equations, there is but one way of doing it, which is quite definite, and leads to a speed which cannot possibly exceed that of light, since it is the speed $(\mu c)^{-\frac{1}{2}}$ through the dielectric, and cannot be sensibly greater than $3 \times 10^{10}$ centim., though it may be less. Kirchhoff's result is therefore in conflict with Maxwell's statement that the German methods lead to the same results as his. Besides that, Wheatstone's classical result has not been supported by any later results, which are always less than the speed of light, as is to be expected (even in a non-distortional circuit). But a reference to Wheatstone's paper on the subject will show, first, that there was confessedly a good deal of guesswork; and, next, that the repeated doubling of the wire on itself made the experiment, from a modern point of view, of too complex a theory to be examined in detail, and unsuitable as a test.

XVI. A Theory of Glacier Motion. $B y$ R. Mountford DeELeY, F.G.S.*

SOME years have now elapsed since the question of glacier 5 motion was brought prominently before the scientific world by the publication of a number of valuable treatises and letters on the glaciers of the Swiss Alps. Each new theory of glacier-motion, as it was given to the world, necessitated further observation of the phenomena presented by glaciers, or gave increased interest to the many interesting properties of ice. In this way a vast amount of information has been collected by numerous trained observers, about which there is little dispute; but to the simple question, " Why does a glacier move?" a great variety of answers would still be given. Indeed, it canmot be said that any substantial progress has been made, for though, as we have seen, a considerable number of theories have been framed, no one of them has yet been anything like generally accepted. Principal J. D. Forbes insisted upon the problem being treated as one of pure mechanics; and to him we largely owe that knowledge of glacier phenomena which Professor Tyndall and others have so ably worked out. Still the old question remains unanswered. We know how the glacier moves, but cannot say why it moves. To add another theory to the already long list may be regarded as tending to make matters

* Communicated by the Author. 
still worse; but I venture to think that, as the heat of former discussion has now dissipated itself, and no theory has succeeded in standing the test of time, another attempt is justifiable. I do not underrate the splendid work done by Rendu, Forbes, Tyndall, Thomson, and many other eminent men; for, as I have previously indicated, to them we owe a series of observations on glacier-motion and structure which will always rank high among the scientific achievements of the present century. Still, the exact details of the process which goes on within a glacier as it slowly changes its form, accommodates itself to the ever-varying shape of its rocky channel, and moves downwards with a differential motion under the action of gravity, is still legitimate matter for speculation.

The theories now in the field are too well known to render any detailed reference to them necessary; I will therefore content myself with stating, as simply as possible, what may be regarded as a purely mechanical explanation of the observed facts.

It should be borne in mind that all the changes of form which a body undergoes, provided no increase or decrease of bulk takes place, may be regarded as due to what is called simple shear. Take a pile of notepaper, or a pack of cards, and displace it a little so that instead of standing vertically it forms an inclined heap. Change of form has taken place without change of bulk. The distortion has been accomplished by the shearing of the pile in planes parallel and coincident with the sheets of paper or card. Instructive examples may be seen in the quires of notepaper piled up in various forms in shop windows. Every change of outline suffered by a glacier, if we disregard melting and the small internal changes of bulk produced by pressure \&c., is due to a shear of ice plane over ice plane. The resistance offered to the sliding of the particles of one plane over the particles of another plane is called friction; and the resistance they offer to being torn asunder is called cohesion. Now the rigidity, elasticity, \&c., of a substance will depend upon the qualities and values of these two properties. For instance, cast iron breaks when put in tension without pulling out to any extent; for the cohesion of its particles is not sufficient to overcome internal friction, and allow much more than elastic shear to take place before breaking. On the other hand, the cohesion between the particles of wrought iron is so great that it stretches out- that is shears-and becomes heated by the resulting friction.

We are now in a position to understand an experiment 
which will be of great value to us further on. Take a plate of steel, say twenty-four inches long, three inches deep, and half an inch thick. Firmly fix one end to a suitable support so that the steel plate shall form a girder with its greatest depth in a vertical position. Then distribute a number of weights along the length of the bar. It at once becomes deflected; that is shear, elastic shear, is produced in a manner somewhat analogous to that in the pile of notepaper. We will now drill a row of holes along the plate; and when this has been done, the girder, having been weakened, will be found to have taken a still greater amount of set. Still further increase the set by drilling several rows of holes. So far all the operations have been possible ones; but I must now draw upon the imagination somewhat, and perform operations which cannot be carried out in practice. Take the material removed from the numerous perforations in the plate, and replace it so that the plate becomes whole again. It is evident that though again solid, only that metal which formed part of the original perforated plate is in a state of strain, that filling the holes taking no share of the load. We will again drill a number of holes, this time in the spaces between the older perforations, and another increase will take place in the deflection of the plate. A strain will also be put upon the metal in the first series of holes bored; and, in addition, a greatly increased strain thrown upon what remains of the original plate. By repeating the operation the girder could be deformed to any desired extent, and, if necessary, such a violent strain thrown upon any one point that local rupture would ensue. The shear we have produced, and also that which took place in the pile of paper, can now be compared with that taking place in an ice-stream. Place the steel plate horizontally on a map of a glacier drawn to a suitable scale, the end which was used as a support being placed near the edge of the ice, and the other end, which carried the weights, near the centre of the glacier. The differential motion Tyndall so carefully measured will then be found to be similar to, if not congruent with, the shear which the steel plate has undergone. It must be remembered that the ice is a girder of great depth, and the shear surfaces are therefore approximately plane, whereas in the experimental plate they were surfaces of considerable curvature. What is the bearing of the knowledge thus gained upon the question of glacier-motion?

Ice, though hard and brittle, is still an elastic substance. When in mass it undergoes a certain amount of deformation like any other body, by virtue of its own weight and elasticity. 
If a mountain-mass could be freed from the attraction of the earth, it would, owing to the elasticity of its component rocks, increase in height by many feet. Every change of atmospheric pressure produces an exceedingly small rise or fall of the earth's surface. The ebb and flow of the tides has a similar effect upon the land in the neighbourhood of the coastlines; indeed, every substance not absolutely rigid (and absolutely rigid substances do not exist) must, when subjected to any stress whatever, show a corresponding strain or deformation.

A glacier upon whose mass we will suppose gravity has previously had no effect is suddenly put within the sphere of the earth's attraction. It instantly undergoes a. change of form. In fact strains are produced in the ice each proportional to the measure of the corresponding stress, and the ice takes a small step in a downward direction, that is in the direction of least resistance. If the glacier rested in a valley with straight smooth sides, the ice would descend bodily and continue to slide until stopped by an angle in its channel or other obstruction. Even on an uneven or crooked bed a certain amount of slide occurs until the bending strains are proportional to the stresses. We therefore have two kinds of motion-one a bodily slide in a downward direction, and another descent due to the differential motion of the ice not in contact with the ground, the resultant motion being proportional to these two components. De Saussure supported a sliding theory; but in a rocky uneven gorge, before continuous sliding can take place, the ice must be capable of continually changing its form to creep over the inequalities of its rocky bed. Of course, when ice is pressed hard against a boss of rock, thawing must go on at a temperature below the ordinary freezing-point, a portion of the water produced recongealing on liberation. A similar effect is obtained by passing a wire over a block of ice and hanging a weight upon it. The wire passes through the mass without splitting it into two portions. That glaciers do slide is capable of absolute proof. Examine the rocky floor over which a glacier has moved. It is frequently beautifully polished, scratched, and grooved. Stones of all sizes have become embedded in the ice, and as it carried them along, the adjacent rocks against which they were pressed underwent considerable abrasion. The polishing and finer markings are effected by the clay, sand, and smaller stones. In this way many of the inequalities of the ground are worn away by glaciers; and the markings give us conclusive proof, not only of the bodily motion of glaciers, but 
also of their former existence in areas where they are now absent. Such evidence may be seen scattered over almost the whole of Northern and Central Europe.

We have so far only considered the initial motion of a glacier resulting from its weight and elasticity. As soon as the strains became proportional to the stresses (we shall be sufficiently accurate if we regard the problem as a kinematical one), all movements ceased; and, without the existence of some further reason for motion, the ice would remain motionless in its bed. Generally speaking the strains produced by weight alone would not be sufficient to cause more than local rupture in such a hard material. The distortion so far undergone may be considered as one of elastic shear.

Displace a glacier by an equal bulk of firm clay. The clay, being heavier than the ice and nothing like so capable of resisting shear, ought, on the fracture theory, to move; but in reality it would remain in the valley for a lengthened period without showing any signs of continuous motion. Now, if the weight of the clay is not sufficient to produce shear and give rise to motion, why should gravity act so powerfully upon each particle of ice, a much harder and more cohesive material, and cause the whole to move like a sluggish river? Fracture cannot occur until an amount of general movement has taken place sufficient to throw strains upon some portions greater than the ice at such points can withstand without rupture. What we have, therefore, to explain is how this general movement comes about: fracture and regelation are mere secondary phenomena arising from glacier motion.

Now we have seen how a glacier takes an initial set, or elastic shear, by reason of its weight and elasticity. Every portion of the mass is supporting a certain proportion of the load; and every internal particle of ice which at any time thaws and ceases to be an element of strength gives rise to a further set or movement. On the other hand, when the water in a cavity freezes, it does not begin to afford any support until a strain is thrown upon it by the differential motion of surrounding particles. Gravity may therefore give rise to a slow but continuous change of form in an elastic substance in the interior of which liquefaction and resolidification are constantly going on. Changes of bulk (I do not mean change of form or reduction of mass by thawing) do not take place to any extent in a glacier as a whole ; what we have to consider is shear, a sliding of particle over particle, producing change of form or distortion, whether interual or external. In an experiment with the steel plate it was proved that by destroying at numerous points the support afforded by the metal, 
then restoring the continuity of the mass, and repeating the operation, any amount of deformity could be produced. It therefore follows that if it can be shown that constant liquefaction and resolidification is going on within a glacier, we have all the essential requisites for producing glacier-motion.

It would be difficult to say which is the most interesting of the numerous properties of water in its liquid and solid states. We are in the habit of considering its freezing-point as being a fixed temperature; but Professor W. Thomson proved experimentally that the melting-point of ice is lowered by about the seventy-fifth part of a degree Fahrenheit for every additional atmosphere of pressure. That is, ice under a pressure of about eleven hundred pounds per square inch melts at $31^{\circ}$ instead of $32^{\circ}$ Fahr. Hold a slab of lake-ice in the sun's rays. The heat attacks the ice in its interior and produces liquid flowers of great beauty. Watch a flower as it derelops! Suddenly a clink is heard, and a bright vacuous spot appears like a silver bead in the centre of the flower. Before the spot formed, the water in the cavity was in a state of tension, and the clink heard was the vibration produced by the tension overcoming the cohesion of the particles of water, and causing rupture. A condition somewhat similar to that of tension, or negative pressure, exists in water when freed from air and heated in a bath of linseed-oil and oil of cloves. In this way it has been raised, while under a pressure of one atmosphere only, to a temperature of $356^{\circ} \mathrm{F}$. Now $356^{\circ} \mathrm{F}$. would indicate a cohesive force equal to nearly ten atmospheres. The negative pressure of the water formed by the internal melting of ice, in the absence of air-bubbles, probably exceeds this amount. If positive pressure lowers the freezing-point, negative pressure should raise it. From this it follows that the water in a liquid flower or glacier cavity is surrounded by and in contact with ice sufficiently cold to freeze it directly the source of heat which produced liquefaction is removed. Professor Tyndall placed some lake-ice containing cavities filled with water and air in a warm-water bath. As soon as a cavity was reached by the melting of its walls the inclosed air-bubble at once shrank to a small proportion of its original volume, showing that even in this case the freezing-point of the water was above that of the surrounding ice. Other experiments which it is needless to relate have been made confirming this fact.

During fine sunny weather, or even with warm rain, glaciers have been shown to move more rapidly than when the weather is cold and snowy; and if the glacier could be cooled several degrees below the freezing-point, and shaded Phil. Mag. S. 5. Vol. 25. No.153. Feb. 1888. 
from radiant heat, all motion would cease ; for experiment tells us that it is only when at or about the freezing-point that ice is what Principal Forbes called viscous. It is interesting to note that those particles of ice which have to carry the greatest load, that is, are in a state of compression, are the most likely to be the first melted; a fact which not only accounts for the inability of ice to extend much when in tension, but increases the efficacy of liquefaction and recongelation to produce glacier-motion.

I will not attempt to refer to the bearing of this theory upon ribboned structure and the many other interesting peculiarities of glacier ice, the present opportunity not being convenient for their detailed treatment.

\section{Intelligence and Miscellaneous Articles.}

ON THE INFLUENCE OF LIGHT UPON THE ELECTRIC DISCHARGE. BY E. WIEDEMANN AND H. EBERT.

PROF. H. HERTZ* in a recent paper, "On the Influence of Ultra-Violet Light upon the Electric Discharge," has described a series of experiments which show that light-rays, and, according to Prof Hertz, exclusively the extreme ultra-violet rays, exert a certain influence upon the passage of electricity in a sparkdischarge. It remained uncertain whether this influence was of a primary nature, or whether the passage of the discharges was effected by secondary impulses produced by the action of the light. In order to obtain a nearer insight into the conditions and nature of the phenomenon, we have, in the first place, repeated Hertz's experiment, and always with complete success; then we have further varied the conditions of the experiment, and have thus obtained the following results. As source of light we nearly always employed an electric arc-lamp ; in particular cases burning magnesium.

(1) The phenomenon is seen with the greatest regularity not only with the discharge of an induction-coil, but also when a Holtz machine is used, that is, with statical electricity, if the discharge upon which the light acts is contained in a secondary circuit of a Holtz machine, the spark-length of the primary circuit being varied by means of a spark-micrometer. Illumination of the discharge produces a lowering of the potential necessary for the passage of the electricity.

(2) In order to study the influence of the light during the passage of electricity in the passive discharge, one pole of the machine was connected with the earth; the electricity accumulated upon the

Wied. Ann. xxxi. p. 983 (1887). 